\title{
A case of entecavir-induced Fanconi syndrome
}

\author{
Teruhiro Fujii ${ }^{1,2} \cdot$ Kentaro Kawasoe ${ }^{1,2} \cdot$ Akihito Ohta $^{1} \cdot$ Kosaku Nitta $^{2}$
}

Received: 7 March 2019 / Accepted: 23 May 2019 / Published online: 1 June 2019

(c) Japanese Society of Nephrology 2019

\begin{abstract}
Acquired Fanconi syndrome has been associated with the long-term ingestion of several nucleoside analogs used to treat chronic hepatitis B virus infection. However, the nucleoside analog entecavir has not been found to cause nephrotoxicity. We report a case of entecavir-induced Fanconi syndrome. Our patient was a 73-year-old man admitted to our hospital because of renal dysfunction. He also presented with hyperaminoaciduria, renal diabetes, phosphaturia, hypophosphatemia, hypokalemia, hypouricemia, and hyperchloremic metabolic acidosis, supporting a diagnosis of Fanconi syndrome. In this case, the cause of Fanconi syndrome was most likely entecavir, which had been administered as needed depending on his renal function for 5 years. After drug discontinuation and replacement with tenofovir alafenamide fumarate therapy once a week, the patient's kidney function recovered and electrolyte anomalies partially improved. We highlight the fact that entecavir may induce severe renal dysfunction, which can cause the development of Fanconi syndrome; therefore, close monitoring of proximal tubular function is recommended during entecavir therapy.
\end{abstract}

Keywords Entecavir $\cdot$ Fanconi syndrome $\cdot$ Nucleotide analog $\cdot$ Chronic hepatitis B

\section{Introduction}

Currently approved agents for the treatment of chronic hepatitis B virus (HBV) infection are interferons and nucleoside analogs. Compared with interferons, nucleoside analogs not only achieve higher rates of HBV DNA suppression but also are considered safer [1]. Entecavir (ETV) is a highly effective antiviral nucleoside analog reverse transcriptase inhibitor and a preferred first-line agent for the treatment of chronic HBV infection [2].

Renal dysfunction during the course of antiviral treatment for chronic hepatitis B is one of the most serious side effects of nucleoside analogs. Recently, there have been reports of specific adverse events from long-term exposure to these agents, mostly nephrotoxicity, which may be associated with Fanconi syndrome [3].

Teruhiro Fujii

terubassist@hotmail.co.jp

1 Division of Nephrology, Department of Medicine, Tokyo Metropolitan Komagome Hospital, 3-18-22, Honkomagome, Bunkyo-Ku, Tokyo 113-0021, Japan

2 Department IV, Internal Medicine, Tokyo Women's Medical University, 8-1, Kawadacho, Shinjuku-Ku, Tokyo 162-8666, Japan
Adefovir dipivoxil (ADV) and tenofovir disoproxil fumarate (TDF) are the main causes of nucleoside analog-induced Fanconi syndrome, which is usually treated by reducing the drug dose and by switching to another nucleoside analog [4]. However, there has been no report of Fanconi syndrome induced by ETV. Here, we report a case of Fanconi syndrome in a patient undergoing treatment with ETV for chronic hepatitis B.

\section{Case report}

A 73-year-old man was admitted to our Department of Nephrology because of renal dysfunction. He was healthy and had no family history of kidney disease, hypertension, or liver cirrhosis. When the patient was 66 years old, he underwent bone marrow transplantation for the treatment of acute myelogenous leukemia and was taking tacrolimus hydrate for graft-versus-host disease for 5 years. He had reportedly been stable after the transplantation; however, his renal function gradually worsened, with serum creatinine $(\mathrm{Cr})$ levels at $1.2 \mathrm{mg} / \mathrm{dL}$, because of tacrolimus hydrate administration at the age of 67 years, which depended on symptoms of graft-versus-host disease and renal function. De novo hepatitis B virus infection was identified after the bone 
marrow transplantation, and treatment with $0.5 \mathrm{mg}$ ETV every other day was started when the patient was 68 years old. One year later, he developed right hydronephrosis from ureteral stones. Subsequently, a urinary cytology indicated a possible malignant tumor and, therefore, right nephrectomy was performed. The resected right kidney showed no signs of malignancy but revealed lymphocyte infiltration, mild fibrosis of the interstitium, and glomerular sclerosis due to hydronephrosis. The patient's general condition was stable after the nephrectomy. Regarding renal function, his serum Cr levels were approximately $2 \mathrm{mg} / \mathrm{dL}$. After the right nephrectomy, the patient's ETV dosage was adjusted to $0.5 \mathrm{mg}$ twice a week.
Once the patient turned 73 years, his renal dysfunction rapidly progressed over a 4-month period, and his serum $\mathrm{Cr}$ levels increased to $4.12 \mathrm{mg} / \mathrm{dL}$, at which point he was admitted to our hospital for examination. On admission, his physical examination did not reveal muscle weakness, fatigue, bone pain, or dryness symptoms, such as xerophthalmia and xerostomia. His blood pressure was 111/60 mmHg. He had no exposure to heavy metals and was not taking any medications, Chinese herb tea or supplements other than entecavir.

Table 1 shows the urinalysis and blood examination results. Urinalysis showed glucosuria $(3+)$ and proteinuria $(2+)$. Despite the detection of glucosuria, his blood glucose level was $91 \mathrm{mg} / \mathrm{dL}$ and $\mathrm{HbA} 1 \mathrm{c}, 5.9 \%$, indicating that the

Table 1 Laboratory findings on admission

\begin{tabular}{|c|c|c|c|c|c|}
\hline \multicolumn{2}{|l|}{ Urinalysis } & \multicolumn{2}{|l|}{ Blood cell count } & \multicolumn{2}{|l|}{ Immuno-serology } \\
\hline Urinometry & 1.014 & WBC & $12.800 / \mu \mathrm{L}$ & $\operatorname{IgG}$ & $1836 \mathrm{mg} / \mathrm{dL}$ \\
\hline $\mathrm{pH}$ & 6.5 & $\mathrm{RBC}$ & $255 \times 10^{4} / \mu \mathrm{L}$ & IgG4 & $62 \mathrm{mg} / \mathrm{dL}$ \\
\hline Protein & $2+$ & $\mathrm{Hb}$ & $9.0 \mathrm{~g} / \mathrm{dL}$ & $\operatorname{IgA}$ & $318 \mathrm{mg} / \mathrm{dL}$ \\
\hline Occult blood & - & Plt & $19.9 \times 10^{4} / \mu \mathrm{L}$ & IgM & $90 \mathrm{mg} / \mathrm{dL}$ \\
\hline Sugar & $3+$ & & & C3 & $115 \mathrm{mg} / \mathrm{dL}$ \\
\hline RBC & $1-3 / \mathrm{HPF}$ & Blood chemistry & & $\mathrm{C} 4$ & $21.6 \mathrm{mg} / \mathrm{dL}$ \\
\hline WBC & - & ТP & $7.6 \mathrm{~g} / \mathrm{dL}$ & $\mathrm{CH} 50$ & $67.8 \mathrm{U} / \mathrm{mL}$ \\
\hline \multirow[t]{2}{*}{ Cast } & - & Alb & $3.2 \mathrm{~g} / \mathrm{dL}$ & ANA & $<40$ \\
\hline & & BUN & $30 \mathrm{mg} / \mathrm{dL}$ & anti-SS-A antibody & $(-)$ \\
\hline Urinary chemistry & & $\mathrm{Cr}$ & $4.12 \mathrm{mg} / \mathrm{dL}$ & anti-SS-B antibody & $(-)$ \\
\hline UP & 1.4 g/day & UA & $3.0 \mathrm{mg} / \mathrm{dL}$ & kappa/lamda light chain ratio & 1.96 \\
\hline Alb & $0.122 \mathrm{~g} /$ day & $\mathrm{Na}$ & $141 \mathrm{mEq} / \mathrm{L}$ & M protein & $(-)$ \\
\hline$\beta 2 \mathrm{MG}$ & $158161 \mu \mathrm{g} / \mathrm{L}$ & $\mathrm{K}$ & $2.4 \mathrm{mEq} / \mathrm{L}$ & & \\
\hline NAG & $21.5 \mathrm{IU} / \mathrm{L}$ & $\mathrm{Cl}$ & 114 mEq/L & Blood gas (venous) & \\
\hline $\mathrm{FeK}$ & $67.3 \%$ & $\mathrm{Ca}$ & $7.7 \mathrm{mg} / \mathrm{dL}$ & $\mathrm{pH}$ & 7.25 \\
\hline FeUA & $67.2 \%$ & iP & $2.1 \mathrm{mg} / \mathrm{dL}$ & $\mathrm{HCO}^{-}$ & $14 \mathrm{mEq} / \mathrm{L}$ \\
\hline $\mathrm{FeCa}$ & $3.54 \%$ & $\mathrm{Mg}$ & $2.4 \mathrm{mg} / \mathrm{dL}$ & $\mathrm{CO} 2$ & $33 \mathrm{mmHg}$ \\
\hline Tmp/GFR & $0.23 \mathrm{mg} / \mathrm{dL}$ & AST & $25 \mathrm{IU} / \mathrm{L}$ & Base excess & $-12.1 \mathrm{mEq} / \mathrm{L}$ \\
\hline$\% \mathrm{TRP}$ & $10.9 \%$ & ALT & $14 \mathrm{IU} / \mathrm{L}$ & Anion gap & 11.6 mEq/L \\
\hline \multirow[t]{8}{*}{ Bence Jones protein } & $(-)$ & LDH & $168 \mathrm{IU} / \mathrm{L}$ & & \\
\hline & & ALP & $259 \mathrm{IU} / \mathrm{L}$ & Infection & \\
\hline & & Glu & $91 \mathrm{mg} / \mathrm{dL}$ & HBsAg & $(-)$ \\
\hline & & $\mathrm{HbA1c}$ & $5.9 \%$ & HBV-DNA & $<1.3 \mathrm{Log} \mathrm{IU} / \mathrm{mL}$ \\
\hline & & $1,25(\mathrm{OH})_{2} \mathrm{D}$ & $15.6 \mathrm{pg} / \mathrm{mL}(20.0-60.0)$ & & \\
\hline & & intact PTH & 99 pg/mL (15.8-68.3) & & \\
\hline & & BAP & $8.4 \mu \mathrm{g} / \mathrm{L}(3.7-20.9)$ & & \\
\hline & & TRACP5b & 361 mU/dL (170-590) & & \\
\hline
\end{tabular}

$R B C$ red blood cell, $W B C$ white blood cell, $U P$ urinary protein, $A l b$ albumin, $\beta 2 M G \beta 2$ microglobulin, $N A G N$-acetyl- $\beta$-D-glucosaminidase, $F e K$ fractional excretion of potassium, $\mathrm{FeUA}$ fractional excretion of uric acid, $\mathrm{FeCa}$ fractional excretion of calcium, TmP/GFR tubular maximal transport of phosphate reabsorption to the glomerular filtration rate transport, \%TRP tubular reabsorption of phosphate, $M$ protein monoclonal protein, $\mathrm{Hb}$ hemoglobin, $\mathrm{Plt}$ blood platelet, $\mathrm{TP}$ total protein, $\mathrm{BUN}$ blood urea nitrogen, $\mathrm{Cr}$ creatinine, $\mathrm{UA}$ uric acid, $\mathrm{Na}$ sodium, $\mathrm{K}$ potassium, $\mathrm{Cl}$ chloride, $C a$ calcium, $i P$ inorganic-phosphate, $M g$ magnesium, $A S T$ aspartate transaminase, $A L T$ alanine transaminase, $L D H$ lactate dehydrogenase, $A L P$ alkaline phosphatase, Glu glucose, $H b A l c$ hemoglobin A1c, $1,25(\mathrm{OH})_{2} \mathrm{D}, 1,25$ dihydroxyvitamin-D, intact $P T H$ intact parathyroid hormone, $B A P$ bone specific alkaline phosphatase, TRACP5b tartrate-resistant acid phosphatase $5 \mathrm{~b}, I g G$ immunoglobulin $\mathrm{G}, I g G 4$ immunoglobulin G4, IgA immunoglobulin A, IgM immunoglobulin M, C3 complement3, C4 complement4, CH50 complement hemolytic activity, ANA anti-nuclear autoantibody, anti-SS-A antibody anti-Sjögren's syndrome-A antibody, anti-SS-B antibody anti- Sjögren's syndrome-B antibody, $\mathrm{HCO}^{-}$bicarbonate, $\mathrm{CO} 2$ carbon dioxide, $H B s \mathrm{Ag}$ hepatitis B surface antigen, $H B V-D N A$ hepatitis B virus deoxyribonucleic acid 
cause of glucosuria was renal diabetes. His urinary protein and albumin excretion levels were $1.4 \mathrm{~g} /$ day and $0.122 \mathrm{~g} /$ day, respectively.

Measurement of blood electrolytes showed hypokalemia (potassium, $2.4 \mathrm{mEq} / \mathrm{L}$ ), hypocalcemia (calcium, $7.7 \mathrm{mg}$ / dL), hypophosphatemia (phosphorus, $2.1 \mathrm{mg} / \mathrm{dL}$ ), and hypouricemia (uric acid, $3.0 \mathrm{mg} / \mathrm{dL}$ ). Blood gas analysis showed $\mathrm{pH} 7.25, \mathrm{HCO}_{3}{ }^{-} 14.0 \mathrm{mEq} / \mathrm{L}$, and metabolic acidosis with a normal anion gap. The normal anion gap suggested that the cause of metabolic acidosis was renal tubular acidosis.

Moreover, fractional excretion of potassium was $67.3 \%$ (normal range, 10-20\%), fractional excretion of uric acid was $67.2 \%$ (normal range, $4-11 \%$ ), and the ratio of the renal tubular maximum reabsorption rate of phosphate to glomerular filtration rate (TmP/GFR) was $0.23 \mathrm{mg} / \mathrm{dL}$ (normal range $2.3-4.3 \mathrm{mg} / \mathrm{dL}$ ). Based on the above findings, Fanconi syndrome was suspected and a urinary amino acid analysis was conducted. The analysis revealed that the urinary concentrations of 19 of the 41 amino acids tested were above normal values (Table 2) and that the bone mineral density was normal. Taking together the patient's hyperaminoaciduria, renal diabetes, phosphaturia and hypophosphatemia, hyperchloremic metabolic acidosis, proteinuria, and other characteristic electrolyte abnormalities of blood and urine, we established a diagnosis of Fanconi syndrome.

As potential causes of primary and secondary Fanconi syndrome, we ruled out factors such as heavy metals,

Table 2 Urinary amino acid analysis

\begin{tabular}{lcl}
\hline Aminoaciduria & $\mu \mathrm{mol} /$ day & Normal values \\
\hline Aspartic acid & 22.9 & $\leqq 12.7$ \\
Threonine & 1350.5 & $79.9-528.3$ \\
Serine & 1083.6 & $208.8-1020.0$ \\
Asparagine & 437.9 & $60.7-372.3$ \\
Glutamic acid & 252.5 & $11.3-42.7$ \\
Glutamine & 4614.5 & $207.0-1357.3$ \\
Alanine & 4082.0 & $141.2-833.9$ \\
Citrulline & 588.4 & $13.5-55.6$ \\
$\alpha$-Aminobutyric acid & 116.1 & $\leqq 27.1$ \\
Valine & 1313.8 & $24.8-82.2$ \\
Cysteine & 840.8 & $23.7-170.9$ \\
Methionine & 65.7 & TR-20.2 \\
Isoleucine & 347.4 & $7.5-23.5$ \\
Leucine & 673.4 & $24.6-89.3$ \\
Tyrosine & 632.3 & $50.6-308.4$ \\
Phenylalanine & 801.5 & $27.2-110.2$ \\
Tryptophan & 151.6 & $20.7-150.7$ \\
Ornithine & 466.9 & $6.9-43.9$ \\
Arginine & 373.1 & $11.6-54.8$ \\
\hline
\end{tabular}

$T R$ means trace paraprotein-related kidney disease such as monoclonal gammopathy and multiple myeloma, and autoimmune diseases like IgG4-related disease and Sjögren's syndrome; however, we suspected that ETV was the causative agent. Hence, ETV was discontinued and oral administration of sodium bicarbonate and potassium chloride was started. In addition, ETV was replaced by the alternative nucleoside analog tenofovir alafenamide fumarate (TAF), which was administered once a week. Following this treatment, the patient's renal function gradually recovered; 4 months later, his serum $\mathrm{Cr}$ levels decreased to $2.86 \mathrm{mg} / \mathrm{dL}$ and partial improvement in the electrolyte anomalies and urinary tubule markers was observed (Fig. 1).

\section{Discussion}

Fanconi syndrome is characterized by diminished reabsorption of solutes, such as amino acids, sugars, uric acid, bicarbonate, and phosphate, because of proximal tubular injury. Fanconi syndrome is often associated with hypophosphatemic osteomalacia due to the loss of phosphate in the urine and impaired activation of vitamin $\mathrm{D}$ in the proximal tubule. In addition to congenital factors, causes of Fanconi syndrome include exposure to heavy metals, such as lead and cadmium, multiple myeloma and Sjögren's syndrome, and drug ingestion. Several cases of drug-induced Fanconi syndrome have been reported, mainly due to the ingestion of antibiotics, valproic acid, anticancer drugs, and nucleoside analogs [5]. In our case, paraprotein-related kidney diseases, such as monoclonal gammopathy and multiple myeloma, were suspected because urinary albumin level was relatively low for the level of urinary protein. However, the patient tested negative for M-protein and Bence Jones protein, and his free light chain ratio was slightly higher than the normal range, which might be due to renal dysfunction. These results did not indicate paraprotein-related kidney disease, and thus, we suspected that ETV was the causative agent. Among nucleoside analogs, ADV and TDF have been reported to cause Fanconi syndrome, often as a consequence of long-term oral administration [4]. In our case, Fanconi syndrome developed after 5 years from the start of ETV treatment. Through a comprehensive search in Medline and Web Japan Medical Abstracts Society, we identified no reported cases of ETV-induced Fanconi syndrome. Therefore, to our knowledge, this is the first report to describe a case of ETV-induced Fanconi syndrome.

Nucleoside analog-induced Fanconi syndrome may occur because of the accumulation of these drugs in renal tubule cells [6]. ADV and TDF are transported from the blood into proximal-tubule cells by renal basolateral transporters of the human organic anion transporter (hOAT) family and are subsequently effluxed from proximal tubule cells into the urine 


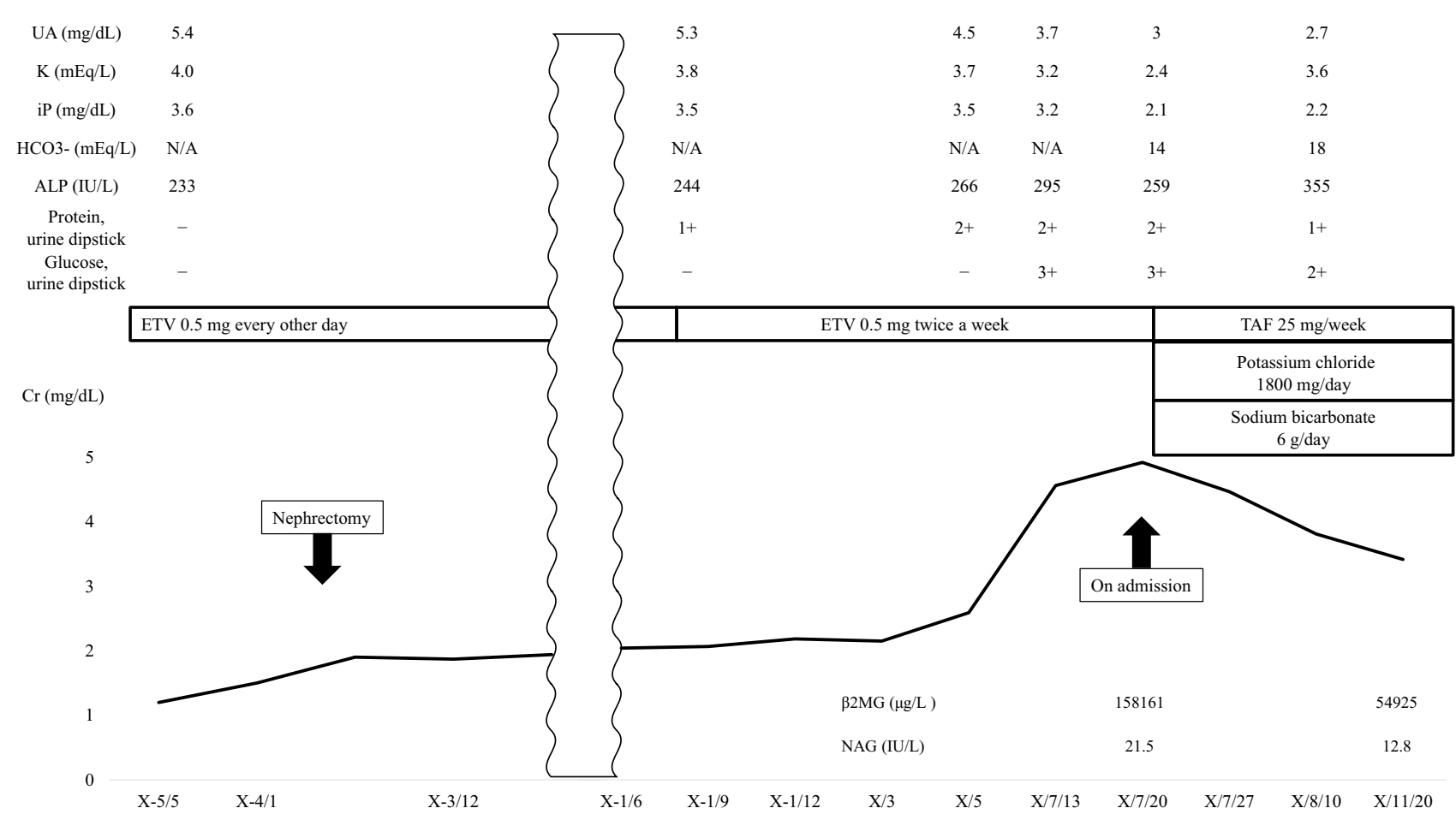

Fig. 1 Clinical course of the patient. $U A$ uric acid, $K$ potassium, $i P$ inorganic-phosphate, $H C O 3$ - bicarbonate, $A L P$ alkaline phosphatase, $C r$ creatinine, ETV entecavir, TAF tenofovir alafenamide fumarate

by the multidrug resistance-associated protein (MRP) efflux pump expressed on the apical membrane [7]. Both these drugs may induce the development of renal tubular injury and Fanconi syndrome when they accumulate in the kidney because of an imbalance between their uptake and excretion in proximal tubule cells [8]. Yang et al. demonstrated that the renal uptake of ETV is likely mediated by hOAT1/3 and human organic cation transporter 2 and that the efflux is mediated by multidrug and toxin efflux extrusion proteins and MRP1 and MRP2 [9]. ETV has a tubular uptake and efflux pathway similar to ADV and TDF. Mandíková et al. demonstrated that a lower risk of cellular accumulation may be expected for ETV in the kidney from a markedly lower affinity of ETV to hOAT1 and a lower cytotoxic effect of ETV in the cells transfected with hOAT1 in comparison to ADV and TDF [10]. Therefore, renal impairment by ETV may be considered less frequent than that by ADV or TDF. In our case, the patient's renal dysfunction and Fanconi syndrome may have been caused by ETV accumulation in renal tubules, in addition to the basal renal damage due to druginduced renal cell damage, and his history of a nephrectomy.

A unique feature of our case was that osteomalacia was not diagnosed, unlike in cases of Fanconi syndrome caused by ADV or TDF. Dose-dependent nephrotoxicity induced by nucleoside analogs can cause renal phosphate wasting by impairing reabsorption in the renal proximal tubule. In turn, chronic loss of phosphate may lead to insufficient bone mineralization. Moreover, metabolic acidosis is also detrimental to bone mineralization. Therefore, loss of phosphate and metabolic acidosis may lead to osteomalacia. In our case, renal phosphate and calcium wasting, low 1,25-dihydroxyvitamin D level, and metabolic acidosis were observed; however, physical symptoms, such as muscle weakness and bone pain, hyperphosphatasemia, and bone mineral density reduction, were not revealed on admission. We considered two reasons as possible causes for these findings. First, phosphate wasting by ETV nephrotoxicity appeared from just prior to admission. As shown in Fig. 1, a rapidly developing electrolyte abnormality including serum inorganic-phosphate level was recognized at the time of admission. Second, renal dysfunction itself might have decreased phosphate excretion. However, the exact cause is unknown because we did not examine fibroblast growth factor 23 level in our case.

Risk factors of nucleoside analog-induced nephrotoxicity, including Fanconi syndrome, have been previously reported $[11,12]$. A high incidence of ADV-associated nephrotoxicity has been identified in patients over 50 years old and patients who have one or several of the following pre-existing conditions: renal dysfunction, liver cirrhosis, diabetes mellitus, and hypertension [11]. On the other hand, the risk of developing TDF-associated nephrotoxicity reportedly increases with age, pre-existing renal dysfunction, concomitant use of nephrotoxic medications, co-morbidities, such as diabetes mellitus and hypertension, and the use of some protease 
inhibitors [12]. ETV is less likely to cause kidney dysfunction than other nucleoside analogs; therefore, further studies and accumulation of cases are warranted to analyze the risk factors and the exact mechanism of ETV-induced nephrotoxicity.

Drug reduction or switching to another nucleoside analog after drug discontinuation is the main therapeutic strategy for Fanconi syndrome induced by ADV and TDF [13, 14]. In most cases, ETV was chosen as the replacing nucleoside analog, and this resulted in the normalization of renal function and clinical improvement. However, in our case, ETV induced Fanconi syndrome and, after switching to TAF as antiviral therapy due to its reported low nephrotoxicity and high effectiveness among nucleoside analogs [15], the patient's kidney function gradually recovered, with partial improvement in his electrolyte anomalies. Therefore, we propose that chronic hepatitis B patients treated with ETV should be as closely monitored as those treated with ADV and TDF.

In summary, we report a case of ETV-induced Fanconi syndrome that illustrated how Fanconi syndrome may be revealed after several years of ETV therapy. Therefore, we suggest that the frequency of electrolyte monitoring in patients receiving ETV should be guided by a high degree of suspicion and regular symptom review. In addition, it is worth noting that complete biochemical recovery after ETV cessation may be protracted despite symptomatic relief.

\section{Compliance with ethical standards}

Conflict of interest The authors have declared that no Conflict of interest exist.

Research involving Human Participants All procedures performed in studies involving human participants were in accordance with the ethical standards of the 1964 Helsinki declaration and its later amendments or comparable ethical standards.

Informed consent Informed consent was obtained from the participant included in the study.

\section{References}

1. Sarin SK, Kumar M, Lau GK, Abbas Z, Chan HL, Chen CJ, Chen DS, Chen HL, Chen PJ, Chien RN, Dokmeci AK, Gane E, Hou JL, Jafri W, Jia J, Kim JH, Lai CL, Lee HC, Lim SG, Liu CJ, Locarnini S, Al Mahtab M, Mohamed R, Omata M, Park J, Piratvisuth T, Sharma BC, Sollano J, Wang FS, Wei L, Yuen MF, Zheng SS, Kao JH. Asian-Pacific clinical practice guidelines on the management of hepatitis B: a 2015 update. Hepatol Int. 2016;10:1-98. https://doi.org/10.1007/s12072-015-9675-4.

2. Terrault NA, Bzowej NH, Chang KM, Hwang JP, Jonas MM, Murad MH, American Association for the Study of Liver Diseases. AASLD guidelines for treatment of chronic hepatitis B. Hepatology. 2016;63:261-83. https://doi.org/10.1002/hep.28156.
3. Fontana RJ. Side effects of long-term oral antiviral therapy for hepatitis B. Hepatology. 2009;49:S185-95. https://doi. org/10.1002/hep.22885.

4. Gara N, Zhao X, Collins MT, Chong WH, Kleiner DE, Jake Liang T, Ghany MG, Hoofnagle JH. Renal tubular dysfunction during long-term adefovir or tenofovir therapy in chronic hepatitis B. Aliment Pharmacol Ther. 2012;35:1317-25. https://doi.org/10.1 111/j.1365-2036.2012.05093.x.

5. Hall AM, Bass P, Unwin RJ. Drug-induced renal Fanconi syndrome. QJM. 2014;107:261-9. https://doi.org/10.1093/qjmed/ het 258 .

6. Chan HL, Fung S, Seto WK, Chuang WL, Chen CY, Kim HJ, Hui AJ, Janssen HL, Chowdhury A, Tsang TY, Mehta R, Gane E, Flaherty JF, Massetto B, Gaggar A, Kitrinos KM, Lin L, Subramanian GM, McHutchison JG, Lim YS, Acharya SK, Agarwal K, GS-US-320-0110 Investigators. Tenofovir alafenamide versus tenofovir disoproxil fumarate for the treatment of $\mathrm{HBeAg}$-positive chronic hepatitis B virus infection: a randomised, double-blind, phase 3, non-inferiority trial. Lancet Gastroenterol Hepatol. 2016;1:185-95. https://doi.org/10.1016/s2468-1253(16)30024-3.

7. Cihlar T, Ho ES, Lin DC, Mulato AS. Human renal organic anion transporter 1 (hOAT1) and its role in the nephrotoxicity of antiviral nucleotide analogs. Nucleosides, Nucleotides Nucleic Acids. 2001;20:641-8.

8. Imaoka $\mathrm{T}$, Kusuhara $\mathrm{H}$, Adachi M, Schuetz JD, Takeuchi K, Sugiyama Y. Functional involvement of multidrug resistanceassociated protein 4 (MRP4/ABCC4) in the renal elimination of the antiviral drugs adefovir and tenofovir. Mol Pharmacol. 2007;71:619-27.

9. Yang X, Ma Z, Zhou S, Weng Y, Lei H, Zeng S, Li L, Jiang H. Multiple drug transporters are involved in renal secretion of entecavir. Antimicrob Agents Chemother. 2016;60:6260-70. https:// doi.org/10.1128/AAC.00986-16.

10. Mandíková J, Volková M, Pávek P, Navrátilová L, Hyršová L, Janeba Z, Pavlík J, Bárta P, Trejtnar F. Entecavir Interacts with influx transporters hOAT1, hCNT2, hCNT3, but not with hOCT2: the potential for renal transporter-mediated cytotoxicity and drugdrug interactions. Front Pharmacol. 2016;6:304. https://doi. org/10.3389/fphar.2015.00304.

11. Ha NB, Ha NB, Garcia RT, Trinh HN, Vu AA, Nguyen HA, Nguyen KK, Levitt BS, Nguyen MH. Renal dysfunction in chronic hepatitis B patients treated with adefovir dipivoxil. Hepatology. 2009;50:727-34. https://doi.org/10.1002/hep.23044.

12. Jafari A, Khalili H, Dashti-Khavidaki S. Tenofovir-induced nephrotoxicity: incidence, mechanism, risk factors, prognosis and proposed agents for prevention. Eur J Clin Pharmacol. 2014;70:1029-40. https://doi.org/10.1007/s00228-014-1712-z.

13. Eguchi H, Tsuruta M, Tani J, Kuwahara R, Hiromatsu Y. Hypophosphatemic osteomalacia due to drug-induced Fanconi's syndrome associated with adefovir dipivoxil treatment for hepatitis B. Intern Med. 2014;53:233-7.

14. Lampertico P, Chan HL, Janssen HL, Strasser SI, Schindler R, Berg T. Review article: long-term safety of nucleoside and nucleotide analogues in HBV-monoinfectedpatients. Aliment Pharmacol Ther. 2016;44:16-34. https://doi.org/10.1111/apt.13659.

15. Wong GL, Seto WK, Wong VW, Yuen MF, Chan HL. Review article: long-term safety of oral anti-viral treatment for chronic hepatitis B. Aliment Pharmacol Ther. 2018;47:730-7. https://doi. org/10.1111/apt.14497.

Publisher's Note Springer Nature remains neutral with regard to jurisdictional claims in published maps and institutional affiliations. 